\title{
Estimating Actual Abundance of European Sousliks: Using UAV Imagery, Pixel Based Image Analysis and Random Forest Classification to Count Souslik Burrows
}

\section{Csongor I. Gedeon ( $\nabla$ gedeon.csongor@atk.hu )}

Institute for Soil Sciences, Agricultural Research Centre, ELKH

Mátyás Árvai

Institute for Soil Sciences, Agricultural Research Centre, ELKH

Gábor Szatmári

Institute for Soil Sciences, Agricultural Research Centre, ELKH

Eric C. Brevik

Southern Illinois University

Tünde Takáts

Institute for Soil Sciences, Agricultural Research Centre, ELKH

\section{Zsofia Kovacs}

Institute for Soil Sciences, Agricultural Research Centre, ELKH

Janos Meszaros

Institute for Soil Sciences, Agricultural Research Centre, ELKH

\section{Research Article}

Keywords: Population size, Random forest, Pixel-based imagery, Image processing, Model stability

Posted Date: December 6th, 2021

DOI: https://doi.org/10.21203/rs.3.rs-1117011/v1

License: (a) (i) This work is licensed under a Creative Commons Attribution 4.0 International License.

Read Full License 
1 Estimating Actual Abundance of European Sousliks: Using UAV Imagery, Pixel Based

2 Image Analysis and Random Forest Classification to Count Souslik Burrows

3 Csongor I. Gedeon* ${ }^{* 1}$, Mátyás Árvai ${ }^{1}$, Gábor Szatmári ${ }^{1}$, Eric C. Brevik ${ }^{2}$, Tünde Takáts ${ }^{1}$, Zsófia

$4 \quad$ A. Kovács ${ }^{1}$, János Mészáros ${ }^{1}$

$5{ }^{1}$ Department of Soil Mapping and Environmental Informatics, Institute for Soil Sciences,

6 Budapest-1022, Herman Ottó út 15., Hungary

$7{ }^{2}$ College of Agricultural, Life, and Physical Sciences, Southern Illinois University, Carbondale,

$8 \quad$ IL, 62901-4403, USA

$9 \quad$ M.Á.: arvai.matyas@atk.hu; G.Sz.: szatmari.gabor@atk.hu; E.B.: eric.brevik@gmail.com; T.

10 T.: takats.tunde@atk.hu; Zs.K.: kovacs.zsofia@atk.hu; J. M.: meszaros.janos@atk.hu

11 * Corresponding author: gedeon@ rissac.hu, Tel: +36 309617524 
Burrowing mammals are widespread and contribute significantly to soil ecosystem services.

However, how to conduct a non-invasive estimation of their actual population size has remained a challenge. Results support that the number of burrow entrances is positively correlated with population abundance and burrows' location indicates their area of occupancy consequently it provides a benchmark for estimating population size. European souslik is an endangered burrowing species in decline across its range. We present an imagery-based method to identify and count animals' burrows semi-automatically by combining remotely recorded RGB images, pixel-based imagery (PBI) and Random Forest (RF) classification.

Field images recorded in four colonies were collected, combined and then processed by histogram matching and spectral band normalisation to improve the spectral distinction between the categories BURROW, SOIL, TREE, GRASS. Raw or processed images were analysed by RF classification to compare the change in accuracy metrics as a result of processing. From accuracy metrics kappa of precision $\left(\kappa_{\text {BURROw }}{ }^{\mathrm{P}}\right)$ and sensitivity $\left(\kappa_{\text {BURROW }}{ }^{\mathrm{S}}\right)$ for BURROW were 95 and $90 \%$ respectively. A 10-time bootstrapping of the final model resulted in coefficients of variation $(\mathrm{CV} \%)$ of $\kappa_{\mathrm{BURROW}}{ }^{\mathrm{S}}$ and $\kappa_{\mathrm{BURROW}}{ }^{\mathrm{P}}$ lower than $5 \%$, moreover $\mathrm{CV} \%$ values were not significantly different between precision and sensitivity scores. The consistency of classification results and balanced precision and sensitivity confirmed the applicability of this approach. 

openings and delineate the areas of occupancy as compared to traditional, more invasive approaches or other computer capacity and end-user expertise demanding methods.

35 Keywords: Population size, Random forest, Pixel-based imagery, Image processing, Model stability 


\section{Introduction}

Ecosystem engineer burrowing mammals occur in five faunal regions (Feldhamer et al. 2007;

Gomes Rodrigues et al. 2016). Their digging changes soil characteristics and resources for other organisms. This makes them important in maintaining ecosystem functions and services (Meadows and Meadows 1991; Hansell 1993; Whitford and Kay 1999; Haussmann 2017) including human health and well-being (Sandifer et al. 2015; Brevik et al. 2020). Several researchers (Davidson and Lightfoot 2007; Ewacha et al. 2016; Lindtner et al. 2019; Swaisgood et al. 2019) have argued that their disappearance has contributed to the significant deterioration of natural grassland ecosystems and loss of related functions and services. However, due to their underground life-style and uneven activity patterns we know little about the dynamics of their population density and abundance (Johnson 1990; Butler 1995).

There is still one widespread but endangered and declining medium-sized, solitary, soildwelling key species of European shortgrass steppes (primary and secondary), the European souslik (Spermophilus citellus, Linnaeus, 1766, souslik hereafter) (Ramos-Lara et al. 2014; Hegyeli 2020). Souslik habitat Pannonic loess and sand steppes are dominated by Festuca rupicola and F. pseudovina species (Šefferová et al. 2008; Erdos et al. 2014; Györi-Koósz and Faragó 2017). Sousliks stay in their individual, underground burrows during inactive periods but they feed on the surface. Burrows go into the soil at an angle of 90 or 25-30 degrees (mounds at the entrances) against the horizontal surface (Ruzic 1978; Gedeon et al. 2012). Burrow mounds and openings can be visually identified from their surroundings if vegetation does not 
cover their visibility. Although soil and environmental characteristics determine how burrow mounds and openings erode or endure and atmospheric, light-shadow conditions can alter their visibility, they remain separable from their surroundings for years.

Estimation of the abundance of endangered burrowing mammals (i.e. ground dwelling sciurids) is generally carried out by visual surveys or counting of burrows as proxies for their abundance or area of occupancy (Biggins et al. 1993; Mcdonald et al. 2011; Willcox et al. 2019). Both methods have their flaws, however, there is a strong correlation between the number of active burrows and actual density (Harper and Batzli 1996; Hubbs et al. 2000). Thanks to sousliks' legal protection in the EU, their abundance should be and as a result has been surveyed in various European countries like Austria, Poland, Czech Republic, Slovakia, Serbia, Bulgaria for several years (Janák et al. 2013). Comparability of monitoring results would require a standardized method to be carried out in different countries, which has not been solved yet. Burrow counting carried out in Hungary since 2000 (Csorba and Pecsenye 1997; Váczi et al. 2019) is a promising method. 20-year data suggest that there (1) is a declining population trend, (2) are sudden extinctions and the population dynamics is asynchronised (Cepáková and Hulová 2002; Stoeva et al. 2016; Gedeon et al. 2017; Győri-Koósz and Faragó 2017; Váczi et al. 2019). Benefits notwithstanding, the current protocol (Váczi et al. 2019) is inappropriate for estimating the actual, numerical abundance of animals in a colony (Hubbs et al. 2000; Hoogland 2013) because (1) the estimated the ratio of the $\frac{\text { Number of burrow openings }}{\text { Burrow system }}$ is inaccurate (Hut and Scharff 1998; Stoeva et al. 2016), (2) it considers an even density, and (3) complete occupation 
of the habitable area. In reality, sousliks show an uneven spatial distribution and density within a habitable area due to both extrinsic (e.g. vegetation, food, soil, terrain) and intrinsic factors (e.g. social structure, life history traits, habitat choice) (Katona et al. 2002). Therefore, an automatized, still accurate, and non-invasive method that can identify and count burrows in a colony's area of occupancy would be welcomed by nature conservation so that changes in their abundance or area of occupancy could be detected in time (Johnson and Burnham 2012; Šumbera et al. 2012).

Traditional survey methods of the abundance or spatial distribution of animal populations have recently been replaced by non-invasively applied conservation drones and image processing techniques (Velasco 2009; Wilschut et al. 2013; Pettorelli et al. 2014; Swinbourne et al. 2018; Wang et al. 2018; Wilschut et al. 2018). These aerial methods can decrease the high costs and labour requirement, overcome difficult access to large, remote areas, and increase accuracy and precision of the estimation. The automated identification of souslik burrows on images would enable us to (1) count the number of burrow openings (BOs) on images quickly and efficiently, (2) follow the change of abundance, density, and distribution of BOs over the entire area of occupancy, and (3) make a more reliable and accurate estimate on the area of occupancy. A basic aerial survey method includes several steps until the manual or automated identification of relevant objects could occur by building an algorithm and then applying a predictive model to identify relevant objects automatically. Various spectral, topographical, or environmental variables may be needed and used to build a robust, flexible model, however the necessary 
number and type of predictors for high accuracy of classification depend primarily on the size of the object to detect and the resolution of images (Boyaci et al. 2017; Berhane et al. 2018a; Vlachopoulos et al. 2020a, b). For the classification of images pixel- or object-based classification (segmentation) algorithms are usually applied. Although object-based imagery (OBI) is considered to perform better (provides higher overall accuracy in classification) it also requires increased computational capacity and a large amount of user processing. Additionally, the relatively small size of the "object" of interest (BOs) and the would-be required small scale of segmentation, and the small number of categories to differentiate indicated a priori that OBI and PBI would perform with similar accuracy. Moreover, we wanted to show a more userfriendly procedure (less computational and processing tasks, simple RGB sensor, less expensive UAV), consequently we chose the PBI (Duro et al. 2012; Berhane et al. 2018b; Qu et al. 2021) in advance for image processing.

Following image processing non-parametric (ensemble) classification methods are more frequently used for data collected by remote sensing (Rokach and Maimon 2006). Different studies have recommended the use of the tree-based random forest (RF) classification algorithm for spectrally noisy, remotely sensed data because of its robustness and superior performance of accuracy metrics over other non-parametric classifiers (Dormann et al. 2013; Lillesand et al. 2015; Berhane et al. 2018c). RF generates a collection of de-correlated, independent trees, and then averages them (Breiman 2001). Thanks to its popularity there are readily available statistics books that explain its benefits as compared to other boosting techniques (Belgiu and 
Drăgu 2016; Smalheiser 2017). Its advantages include high-predictive accuracy and

119 applicability with highly correlated variables (Delincé 2017). Both circumstances were expected in our application as we would like to accurately (high-predictive accuracy) identify

121 burrows, and indices used in model building were derived from spectral variables (correlation).

122 Our primary aim in this study was to explore the combination of UAV imagery and PBI with 123 an RF classification technique to identify souslik BOs on images, which are good proxies for 124 the actual abundance and location of sousliks. The premise of our approach was that burrows 125 and other characteristic objects (soil, trees and shrubs, grass) have special-spectral 126 characteristics (spectral signatures) that can be used to identify and differentiate them in 127 remotely sensed imageries. Another aim of this study was to support the notion of aggregated souslik burrows in a colony. We expected this special pattern but this premise was needed to 129 be tested to underline the importance of surveying large areas for an accurate estimation of the number and location of burrows. The final aim was to assess how applicable or useful our method was for detecting and distinguishing active souslik BOs from the surroundings by estimating the RF model's accuracy and stability after image processing. 
We collected images on four souslik colonies including the sampled areas between 1 and 31 July 2019 in Hungary by UAV imagery. Study sites were in coordinate system UTM/Zone 33 vegetation heights from short to medium-height grass (Gedeon et al. 2012). Preliminary studies indicated that tall grass height (mean $>18 \pm 1.5 \mathrm{~cm}$ ) disabled the application of UAV imagery and semi-automated detection due to the obscuration of BOs. Therefore we excluded one site from the analysis in advance. We designated study areas as Bakonykúti, Gerecse I., Gerecse II., and Kisoroszi.

All four colonies were located in the Pannonian grassland ecoregion. Xerophilous loess grassland of Salvio nemorosae-Festucetum rupicolae dominated three colonies (Bakonykúti, the open sand grassland of the Kisoroszi colony (Györi-Koósz and Faragó 2017). Annual grass, perennial herbs, shrubs and small trees dominated all grasslands. Each study site was under legal protection and located in a national park. This allowed little tourism on study sites and they primarily served conservation aims. Grazing by sheep maintained short or medium-short vegetation all year around at all four sites which benefited sousliks' survival and helped detect

152 BOs in the field and on images.

153 We marked the exact location of active animal BOs in the field with red-white-yellow flags.

154 Then we made the first images for each area. Then we removed the flags and repeated the image recording process. This approach enabled us to find almost all BOs on each image visually and 
156

157

158

159

160

161

162

163

164

165

166

167

168

169

170

171

172

173 The image processing started with red, green and blue (RGB) unmanned aircraft system

to use the flag-free images for further processing. The reports of the annual state monitoring and our visual observations of animals or their pellets at the BOs validated all four colonies as active souslik populations, and determined the core area of the colonies reliably.

We conducted the aerial surveys at all four test sites using a UAV with a visible range (RGB) camera onboard after we surveyed the area and marked each BO. After a few pilot surveys (with a 16 Mpx Ricoh GR II camera) on the Gerecse areas, we found a 24 Mpx Fuji X-T20 camera appropriate for the survey (main features: APS-C sensor, focal length of $14 \mathrm{~mm}, \mathrm{f} / 2,8$ $\mathrm{mm}$, Automatic ISO speed, automated exposure time based on the sharpness, colour saturation and brightness of input images). We performed the aerial surveys in a fully automatic flight mode above the study area with image overlap of $80 \%$ and sidelap of $60 \%$ to ensure photogrammetric processing later. Focal length and resolution at an altitude of $25 \mathrm{~m}$ was found to be sufficient for recording BOs on a number of pixels. For later image orthorectification we placed four or more ground control points at each site with a real-time kinematic correction GPS receiver unit (South Galaxy G1) with a maximum $1 \mathrm{~cm}$ error (horizontal and vertical accuracy). We used those ground control points to transform raw images into a Hungarian national coordinate system (EOV/HD72 - EPSG:23700).

\subsection{UAV imagery and spectral data pre-processing}

imagery in the field. A photogrammetric workflow including orthorectification followed UAV imagery, which resulted in an orthophoto mosaic to be processed by a supervised PBI 
176 (Sibaruddin et al. 2018; Vlachopoulos et al. 2020a, b). The latter resulted in RGB derived

177 spectral indices calculated from cloud-free and corrected RGB reflectance bands of any point

178 (pixel) on the image. The raw images were processed in Agisoft Metashape Professional

179 (Version 1.6.1) (Agisoft 2016) to create RGB orthomosaics and digital elevation models (DEM)

180 of the study sites. Thus we ended up with four datasets, each transformed into the UTM/Zone33

181 coordinate system at $1 \mathrm{~cm}$ spatial resolution. At this scale one average burrow opening $(3-4 \mathrm{~cm}$

182 in diameter) covered $~ 7-12$ pixels which was enough to find a "pure" burrow pixel.

183 To increase orthomosaic similarity between images of the study sites for spectral sampling of

184 field categories, consecutive, processing steps were carried out on the mosaic images: histogram

185 matching and spectral band normalization (together as Spectral Normalization, SN). First, we

186 chose the orthomosaic of Kisoroszi site as a reference histogram because atmospheric and

187 flying conditions (at noon, without clouds) were optimal. Then we transformed all other

188 histograms in comparison with that reference site. Secondly, we generated spectral indices

189 based on the raw values of RGB bands. Then those raw values were normalized and centred.

190 This image processing eventually resulted in predictors to be used in Random Forest (RF)

191 classification (Table 1). 


\begin{tabular}{lllll}
$\begin{array}{l}\text { Variable } \\
\text { Acronym }\end{array}$ & Variable's Long Name & Type & Reference or Description & Model \\
\hline R & Red & Spectral & Red colour band & M1.1-2, M2.1-2 \\
G & Green & Spectral & Green colour band & M1.1-2, M2.1-2 \\
B & Blue & Spectral & Blue colour band & M1.1-2, M2.1-2 \\
GLI & Green Leaf Index & Spectral & Louhaichi et al. 2001 & M1.1-2, M2.1-2 \\
CI & Coloration Index & Spectral & Escadafal et al 1994 & M1.1-2, M2.1-2 \\
Intnsty & Intensity & Spectral & Escadafal et al 1994 & M1.1-2, M2.1-2 \\
NGRDI & Normalized Green/ & Spectral & Zarco-Tejada et al. 2001 & M1.1-2, M2.1-2 \\
& Red Difference Index & & & M1.1-2, M2.1-2 \\
RI & Redness Index & Spectral & Bannari et al. 1995 & M1.1 \\
SLP & Slope & Topographical & Travis et al. 1975 & M1.1 \\
ASP & Aspect & Topographical & Zevenberger and Thorne 1987 & M1.1 \\
TPI & Topographioc Position Index & Topographical & Guisan et al. 1999 & M1.1 \\
TRI & Topographic Ruggedness Index & Topographical & Riley et al. 1999 & M1.1 \\
Rghness & Roughness & Topographical & Riley et al. 1999 & M1.1, M2.1 \\
DEM & Digital Elevation Model & Topographical & Hengl and Reuter 2008 & M1.1 \\
Grass height & Grass height & Topographical & Estimated height of surface point & M1.1 \\
Site & Study site & Environmental & Study site &
\end{tabular}

193 Table 1. List and description of input variables (predictors) for the four RF models (M1.1, 1.2,

$1942.1,2.2)$.

195 We digitized the individually flagged BOs on orthomosaics in QGIS (QGIS Development 2021)

196 by placing vector points on the central pixel. The burrow openings were always the darkest

197 pixels on images. Therefore those darkest pixels could always represent the BOs

198 unambiguously. Burrows, trees, grass, and soil were the most characteristic and redundant field

199 cover features of the sites. For the better determination of category specific spectral

200 characteristics, we generated a different number of samples for the categories TREE, GRASS,

201 and SOIL. The more difficult was to distinguish a category from BURROW, the more samples

202 we generated for that category to encompass its natural, spectral variability. Since category

203 GRASS was the noisiest for BURROW, such as shadows by grass tussocks near BOs, we

204 generated a high number of samples representing grass. We found a total number of 93 burrows 
on four sites. In addition we generated 108 tree, 165 soil, and 1383 grass random points on all four sites.

\subsection{Random Forest classification of pixels}

The main purpose of RF classification was to correctly identify BOs on images (category BURROW). Following the recommendations of statistical textbooks (Breiman 2001; Hastie et al. 2017; Breiman et al. 2017) the number of decision trees (ntree) and randomly chosen input variables (mtry) was set to 500 and 4 or 3 , respectively $\left(m\right.$ try $=\mathrm{p}^{1 / 2}$, where $\mathrm{p}$ is the total number of predictors; Breiman, 2001; Table 1). For decreasing model complexity we identified

214 important predictors from the initial set of predictors (spectral, topographic, and environmental variables and indices) based on the variable importance scores (VIS). This approach clarified the simplest but still most robust model for the classification. We used a total of 16 predictors

217 and raw images in the initial Model 1.1 (M1.1). Then the number of predictors were reduced (p 218 = 9) and a new RF model, Model 1.2 (M1.2), was built. The $3^{\text {rd }}$ (Model 2.1, M2.1) $(\mathrm{p}=9)$ and $2194^{\text {th }}$ (Model 2.2, M2.2) models $(\mathrm{p}=8)$ used Spectrally Normalized images. Predictor Site represented the general characteristics of the habitat (Table 1). Since we wanted to see if SN

221 could improve model performance, we ran RF classification on both raw (M1.1 and 1.2) and

222 Spectrally Normalized images (M2.1 and 2.2). Various metrics of overall and per-class 223 accuracy of classification were to tell how successfully each model could identify BOs on 
images. During RF model building $63 \%$ of the original dataset was set for training and $37 \%$ for testing to avoid overfitting (Xu and Goodacre 2018).

\subsection{Evaluation of RF classification}

The correctness of the classification procedure was measured by the number of correct or incorrect classifications of points. Actual values could be "True" or "False", and predicted values could be "Positive" or "Negative". The terms "True Positive" (TP), "False Positive" (FP), "True Negative" (TN), and "False Negative" (FN) covered all options regarding the classification results. The different number and ratio of those probabilities expressed by overall accuracy, Cohen's kappa, precision and sensitivity, and F-score were used to evaluate the performance of the classification models, in other words how accurately the models classified actual pixels into one of the four RF categories. The classification models' overall performance was compared by overall accuracy $(\mathrm{OA} ;(\mathrm{TP}+\mathrm{TN}) /$ Total $)$. Cohen's kappa $(\kappa)$

$$
\kappa=\frac{\text { observed accuracy }- \text { chance agreement }}{1-\text { chance agreement }}
$$

(Cohen 1968; Lillesand et al. 2015) evaluated the agreement between predicted classification and actual values. It evaluated the correctness of the classification performed in comparison to randomly assigning values to one of the four categories. The $\kappa$ can generally range from 0 to 1 .

A positive value would indicate that the classification is better than a random classification, while 0 would indicate that the classification does not perform better than a random 
classification process. According to our premise we punished a misclassification of a souslik burrow $(\mathrm{FN})$ or a misclassification of anything as a burrow (FP) equally as we wanted to

245 identify souslik BOs and the correct or false classification of other objects in the environment (GRASS, TREE, SOIL) was left out of this evaluation. Per-class Cohen's kappa (КURROw) for 247 producers' (Sensitivity, $\mathrm{S}, \mathrm{TP} /(\mathrm{TP}+\mathrm{FN})$ ) and users' accuracies (Precision, $\mathrm{P}, \mathrm{TP} / \mathrm{TP}+\mathrm{FP})$, and

248 F-score $\left(\frac{2 \times S \times P}{S+P}\right)$, which punished extreme values and differences between these two values 249 more than other means, characterised category BURROW specific performance of the models 250 and the relationship between the predicted and actual number of souslik BOs.

\subsection{Model stability}

We evaluated the stability of the best model by a 10-time bootstrapping. The number of decision trees (ntree) and number of input variables (mtry) were set to 500 and 3 respectively. By this iteration process, we could calculate and compare standard deviation (SD) and coefficient of variation (CV\%) of $\kappa$ between models (M2.2, M2.2 $2, \ldots$, M2.2 $\left.{ }_{10}\right)$. One test of model stability involved testing if the variance of $\kappa_{\mathrm{BURROW}}$ for $\mathrm{P}$ and $\mathrm{S}$ (One sample test for variance) (1) was smaller than the average of the $\mathrm{CV} \%$ of $\kappa_{\mathrm{BURR}}$ (ow $\mathrm{P}$ and $\mathrm{S}$ of models $1.1,1.2,2.1$, and (2) could remain $\leq 5 \%$ for either $\mathrm{S}$ or $\mathrm{P}$. We defined $\mathrm{CV} \%$ of a parameter in a population as the ratio of the standard deviation (SD) to the mean and it was a dimensionless measure and considered a measure of stability of a population parameter. In our case, אBURROw for P and S 
could be those parameters whose low variance across the iteration could be used to evaluate the stability of the final RF model. Since the test of a single variance assumed a normal distribution of the population parameters, we tested normality by a modified Kolmogorov-SmirnovLilliefors test for small sample size.

\subsection{Spatial distribution of burrows (mounds or/ and BOs)}

We performed point pattern analysis to investigate the spatial distribution of burrows at the study sites and to explore the potential interaction between the burrows. This meant to justify the need for our method compared to the notion that animals occupy the space randomly or uniformly. We computed the $G(r)$ nearest neighbour distances distribution function and the $F(r)$ empty space function for all study sites, assuming that the burrows constitute a point pattern $\mathbf{X}$ at a study site. This was to explore whether there was an interaction between the location of the burrows, and if there was then what type of interaction it could be. The $G(r)$ function measured the distribution of the distances from an arbitrary burrow to its nearest neighbour (i.e., the burrow nearest to it) that is

$$
G(r)=\mathrm{P}\{d(u, \mathbf{X} \backslash\{u\}) \leq r \mid u \in \mathbf{X}\}
$$

where $u$ is an arbitrary burrow, and $d(u, \mathbf{X} \backslash\{u\})$ is the shortest distance from $u$ to the point pattern $\mathbf{X}$ excluding $u$ itself. The $F(r)$ function measured the distribution of all distances from an arbitrary point of the plane to its nearest burrow that is 


$$
F(r)=P\{d(v, \mathbf{X}) \leq r\}
$$

282

283

284

285

where $v$ is an arbitrary point of the plane, and $d(v, \mathbf{X})$ is the distance from $v$ to the point pattern

X. At all study sites we compared the observed $G(r)$ and $F(r)$ functions to the Poisson point process (complete spatial randomness, CSR), which helped us decide the type of interaction that existed between the BOs. If the observed $G(r)(F(r))$ function was below (above) CSR, then the distribution of BOs at the study site was rather regular. If the $G(r)(F(r))$ was above (below) CSR, then the burrows showed a clustered pattern. To test whether this difference between the observed functions and CSR was significant, we simulated the upper and lower envelopes of CSR at each study site using the Monte Carlo approach.

\subsection{Statistical Analyses}

We performed all statistics using TIBCO Statistica (2018; Version 13.5.0.17) and R (Version 4.0.1.3 (Bivand and Gebhardt 2000; TIBCO Software Inc. 2018; R Core Team 2020). More specifically, the algorithm used for calculating accuracy metrics was developed in $\mathrm{R}$ but the confusion matrix and RF classification were calculated in Statistica. We also used R for analysing spatial pattern, and spectral transformation and index generation using the Raster and RSToolbox packages. If we did not determine a level of significance in a specific analysis then we generally used a $P<0.05$. 

a less than $10 \%$ overall or misclassification error for each model.

\section{Model 1.1 Model 1.2 Model 2.1 Model 2.2}

\begin{tabular}{lcccc}
\hline Overall Accuracy & $\mathbf{9 2 . 4 9}$ & $\mathbf{9 5 . 0 1}$ & $\mathbf{9 2 . 1 0}$ & $\mathbf{9 1 . 3 1}$ \\
Standard Deviation & 1.16 & 0.97 & 1.18 & 1.24 \\
CV\% & 1.30 & 1.00 & 1.30 & 1.40 \\
95\% CI lower & 90.12 & 93.00 & 89.68 & 88.79 \\
95\% CI upper & 94.85 & 97.02 & 95.42 & 93.83 \\
Cohen's Kappa & $\mathbf{0 . 7 6}$ & $\mathbf{0 . 8 4}$ & $\mathbf{0 . 7 6}$ & $\mathbf{0 . 7 4}$ \\
Standard Deviation & 0.04 & 0.03 & 0.04 & 0.04 \\
CV\% & 4.6 & 3.6 & 4.6 & 5.0 \\
95\% CI lower & 0.69 & 0.78 & 0.69 & 0.66 \\
95\% CI upper & 0.83 & 0.90 & 0.83 & 0.81 \\
K $\mathbf{B U R R o w}$ & $\mathbf{0 . 9 0}$ & $\mathbf{1 . 0 0}$ & $\mathbf{1 . 0 0}$ & $\mathbf{0 . 9 5}$ \\
Standard Deviation & 0.07 & 0.00 & 0.00 & 0.05 \\
CV\% & 7.40 & 0.00 & 0.00 & 4.90 \\
$\boldsymbol{K}_{\text {BURRow }}^{\mathbf{S}}$ & $\mathbf{0 . 7 5}$ & $\mathbf{0 . 5 9}$ & $\mathbf{0 . 9 1}$ & $\mathbf{0 . 9 0}$ \\
Standard Deviation & 0.09 & 0.10 & 0.06 & 0.07 \\
CV\% & 11.70 & 16.80 & 6.70 & 8.10 \\
\hline
\end{tabular}

305 Table 2. Overall accuracies and kappa statistics, per-class BURROW kappa for $\mathrm{S}\left(\kappa_{B U R R O W}^{S}\right)$ 
(Table 1). Those eight, spectral predictors remained relevant in models M1.2, M2.1, and M2.2,

311 while other environmental or topographic predictors were ignored based on VIS. The $\kappa$

312 indicated the highest overall performance for M1.2 (Table 2). The other models performed

313 worse according to $\kappa$, though the difference between M1.2 (the highest score) and M2.2 (the

314 lowest score) was small (0.84 vs. 0.74).

Per-class (BURROW) model performance (PBURROW, S $_{\text {BURROW, }} \kappa_{\text {BURROW }}$ ) was the primary focus

of our classification as we wanted to train our models to automatically identify souslik burrows

on images and achieve high and balanced precision and sensitivity. The confusion matrix could and M1.2 (0.75) the lowest F-scores. The other two models' F-scores are in line with the distinction between the accuracy metrics based on raw or Spectrally Normalised data (Fscore $_{\mathrm{M} 1.1}=0.83 ;$ F-score $\left._{\mathrm{M} 2.2}=0.91\right)$. Regarding the difference between $\mathrm{P}_{\mathrm{BURROW}}$ and $\mathrm{S}_{\mathrm{BURROW}}$ values, M2.2 showed the lowest difference (0.08) while M1.2 showed the greatest difference

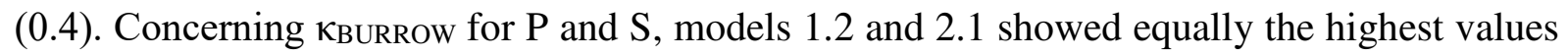
while M2.2 was trailed by 0.05 and M1.1 by an additional 0.05 (Table 2). 
330 the average SD of $\kappa$ of models $1.1,1.2$, and $2.1\left(A V G_{S D}^{M 1.1,1.2,2.1}=0.034, \mathrm{~N}=10\right.$, Chi-Square of $331 \kappa=5.19^{*} 10^{-4}, P=1.36^{*} 10^{-18}$; Table 3 ).

\begin{tabular}{cccccc} 
Iteration & $\begin{array}{c}\text { Cohen's } \\
\text { Kappa } \\
\text { for Precision }\end{array}$ & SD CV\% & $\begin{array}{c}\text { Cohen's } \\
\text { Kappa } \\
\text { for Sensitivity }\end{array}$ & SD CV\% \\
\hline & 1 & 0,96 & $0,044,30$ & 0,85 & $0,078,00$ \\
& 2 & 0,82 & $0,067,10$ & 0,95 & $0,043,80$ \\
& 3 & 0,79 & $0,067,90$ & 0,97 & $0,032,90$ \\
Per-class & 4 & 1,00 & $0,000,00$ & 0,84 & $0,067,20$ \\
(BURROW $)$ & 5 & 0,94 & $0,044,70$ & 0,91 & $0,055,60$ \\
& 7 & 0,97 & $0,033,30$ & 0,94 & $0,044,50$ \\
& 8 & 0,96 & $0,043,70$ & 0,87 & $0,067,00$ \\
& 9 & 0,97 & $0,033,40$ & 0,85 & $0,067,10$ \\
& 10 & 0,85 & $0,067,30$ & 0,82 & $0,077,90$ \\
& 1,00 & $0,000,00$ & 0,90 & $0,055,80$ \\
\hline
\end{tabular}
complete dataset. 
variance of $\mathrm{CV} \%$ of either $\kappa_{\mathrm{BURROW}}$ for $\mathrm{P}$ or $\mathrm{S}$ was significantly smaller than the hypothetical (test) variance of $5 \%\left(\mathrm{CV} \%=5, \mathrm{n}=10\right.$, Chi-Square of $\kappa$ for $\mathrm{P}=0.022, P=1.23 * 10^{-12}$; ChiSquare of $\kappa$ for $\mathrm{S}=0.0023, P=1.17^{*} 10^{-17}$ ). Both the Kolmogorov-Smirnov-Lilliefors and Shapiro-Wilk tests of normality suggested that both $\mathrm{S}$ and $\mathrm{P}$ followed a normal distribution therefore the 'one sample test for variance' could be used and the normality assumption was not violated $(\mathrm{P}:$ Shapiro-Wilk statistic $=0.87, P=0.086 ; \mathrm{KS}$-Lilliefors statistic $=0.23, P=0.10$; S: Shapiro-Wilk statistic $=0.93, P=0.39 ;$ Lilliefors statistic $=0.16, P=0.20$ ).

\subsection{Spatial pattern of BOs}

The point pattern analysis $(\mathrm{G}(\mathrm{r})$ : the nearest neighbour metric, $\mathrm{F}(\mathrm{r})$ : the so-called empty-space function metric) performed on the souslik BOs as proxies for the presence and location of animals indicated clustered spatial patterns at (i) Bakonykúti and Kisoroszi: a statistically significant and strong spatial aggregation point pattern, (ii) Gerecse I.: a statistically significant but week spatial aggregation. A nearly random spatial pattern was present at Gerecse II. (Supplementary Figure S1). The results showed that the spatial distribution of the BOs tended to appear in groups rather than in regular or uniform patterns.

\section{Discussion}


Our results supported the aggregated distribution of souslik burrows. This highlights the need

for the survey of BOs in the whole area of occupancy if spatial boundaries or density changes

361 of colonies over large areas are to be detected. Souslik colonies can cover several hectares consequently the estimation of their abundance or area of occupancy by detecting and counting burrow openings would require a comprehensive survey of large areas. Our UAV-imagery based method has achieved an accurate and reliable detection of burrows semi-automatically. The final model (M2.2) was stable (Stokes et al. 2010; Pettorelli et al. 2014; Stephenson 2019) and showed (1) a balanced number of FN and FP detections, (2) high and balanced per-class

367 (BURROW) accuracy metrics between training and testing subsets or $\mathrm{P}$ and $\mathrm{S}$ values, (3) a userfriendly (less costly and complicated) and straightforward counting method of BOs.

369 Nevertheless, the number of burrow openings of a burrow system belonging to one individual 370 requires a narrower estimation in the future by other proximal sensing techniques. On the other 371 hand, automated detection and counting of BOs were addressed successfully by our method

372 (Supplementary Figure S2). It means that it is ready for getting established in the management 373 of endangered souslik populations or modified to the characteristics of other burrowing 374 mammals' burrows. Censusing of animal populations is a prerequisite for their adequate 375 management (Plumptre 2000; Wang et al. 2018) and BOs provide good proxies for population 376 estimation. 
The use of a 24Mpx RGB sensor, SN including correction and standardisation of illumination and colour by using a reference site improved the accuracy of detection of burrows. The optimal whether conditions for imagery at one site could provide a good reference for correcting other images. Those conditions (less obscuration of BOs and strong natural light illumination) at the reference site could provide less spectral noise or overlap which otherwise could have decreased the performance of RF classification (Agjee et al. 2018). That image processing substantiated RF classification of image pixels into categories effectively with high $\mathrm{P}$ and $\mathrm{S}$. RF classification on raw images resulted in a few FPs (high $\mathrm{P}$, low overestimation) but $\mathrm{S}$ was low and much

387 fewer than P. It meant a high number of FNs, consequently we had missed a number of burrows on those raw images. In a survey it would have resulted in the underestimation of BOs, which would have indicated lower abundance or smaller area of occupancy than the actual one. The unbalance between the number of FNs (high) and FPs (low) of the category BURROW was

391 smoothed out (measured by $\kappa_{B U R R O w}$ for $\mathrm{P}$ and $\mathrm{S}$ ) by the application of SN. That SN could generate a smaller difference between FNs and FPs and still high TPs and TNs (Table 2). 393 Although a small decrease in these accuracy measures was experienced after $\mathrm{SN}$, $\kappa_{\mathrm{BURROW}}$ for $394 \mathrm{~S}$ and $\mathrm{P}$ remained high (0.9) (Congalton 2001) and $\mathrm{FN}^{*} \mathrm{FP}^{-1}$ ratio was balanced. Balanced and 395 still high $\mathrm{S}$ and $\mathrm{P}$ values were superior compared to higher and unbalanced $\mathrm{S}$ or $\mathrm{P}$ values as 396 either under- or overestimation would have been equally misleading (Assal and Lockwood 397 2007). Notwithstanding, those balanced values may not remain stable for other samples so how 398 stable this $\mathrm{FN}^{*} \mathrm{FP}^{-1}$ ratio remains should be tested in the future. 
Results indicated the irrelevance of predictors DEM or micro-relief (unexpected) and Site

400 (expected) in classifying and detecting BOs successfully (M1.2, 2.2). This could be explained

401 by the homogeneity of sites and insignificant difference between the frequency of BOs on

402 elevations and depressions. Grass Height was found to be unimportant in the RF classification

403 but yet shadows generated by grass tussocks could obscure the few cm large BOs. In other

404 words, the shadows could be confused with the darkness of BOs in the RGB channels and

405 frequencies (spectral mixing). This phenomenon may suggest that if further spectral channels

406 were added to sensing by the application of hyper/ multispectral or thermal cameras this

407 obscuration could be distinguishable from natural BOs by unique spectral fingerprints and could

408 decrease the number of FN detections.

409 Literature suggests that aggravated pattern of sousliks and burrows is due to behavioural

410 (nepotism) or habitat characteristics (elevations) (Sherman 1981; Weddell 1989). Therefore,

411 more mountainous souslik habitats with steep slopes like areas in the Mediterranean (e.g.

412 Greece, Bulgaria) might show a different picture from the perspective of site homogeneity and

413 spatial distribution of animals. Certain micro-elevations can help sousliks survive flooding or

414 avoid predators (Katona et al. 2002; Gedeon et al. 2012) but its importance is probably habitat

415 specific and may change by the steep slope of an area.

416 Homogenous habitat and physiological characteristics through the distribution range of a

417 species and model stability are prerequisites to good model transferability though there has not

418 been a standardized way to measure that (Sequeira et al. 2018). Therefore testing the final 
model's stability was crucial for the method's application. To improve stability and the potential of transferability careful attention was paid to sampling, data quality, and model parsimony.

421 For careful sampling, we took images on areas with souslik burrows after meticulously searched

422 the area of occupancy for BOs. Finding quasi-each and verified burrow on sites increased the

423 sample size. BOs appear almost identical (dark holes) and the inter-category spectral

424 differences between BURROW, SOIL, GRASS and TREE were expected to be much larger

425 than the intra-category variation due to different plants, souslik burrows, soil types (calcareous

426 soils including sandy loess, loess or chernozem) at different locations. Sampling at various

427 locations with larger environmental dissimilarities improves model transferability (Wenger and

428 Olden 2012; Sequeira et al. 2018), however, the environmental similarity of souslik habitats in

429 the Pannonian ecoregion did not support colonies sampled far away because it would not have

430 meant larger environmental difference. Consequently, the relative proximity of selected

431 colonies (Figure 1) did not theoretically decrease model transferability. For increased data

432 quality and a more universal model the four datasets were merged and $63 \%$ training part was

433 randomly selected from the combined dataset to train RF classification. The approach of Jin et

434 al. (2018) contributed to build a more location-independent model. For a more parsimonious

435 model, the simplest model with high and balanced accuracy was chosen as the best model

436 (between S and P; small variation of Cohen's kappa and its standard deviation; Table 2). All

437 these considerations have helped and supported that the final model could be a good candidate

438 for a universal model (reasonable, feasible, with good transferability potential) in spite of the 
439

440 441 ground dwelling species (Sequeira et al. 2018).

small number of local populations in this study. Future research will encompass the study of transferability in different souslik populations. Besides, we plan to expand the method into other

442

\section{Acknowledgements}

444 We sincerely thank the Duna-Ipoly and Balaton-felvidéki National Parks, and ranger service 445 particularly for logistical assistance in the field and the opportunity for doing field work on 446 protected areas. We also thank for Nóra Szücs-Vásárhelyi and Judit Matus for their help in data 447 collection, and László Pásztor for his helpful comments on the manuscript.

$449 \quad$ Funding

450 The study was partially funded by the Premium Postdoctoral Scholarship of the Hungarian

451 Academy of Sciences (PREMIUM-2019-390) to GSz and the Scholarship of Human Resource

452 Supporter grants (NTP-NFTÖ-20-B-0022 and NTP-NFTÖ-20-B-0017) to JM and MÁ.

453

454 Declarations

455 The authors declare that there is no either financial or personal conflict of interest that have 456 influenced the work in this paper. 


\section{References}

Agisoft L (2016) AgiSoft PhotoScan Professional (Version 1.2.6)

Agjee NH, Mutanga O, Peerbhay K, Ismail R (2018) The impact of simulated spectral noise on random forest and oblique random forest classification performance. J Spectrosc 2018:1-7. https://doi.org/10.1155/2018/8316918

Assal TJ, Lockwood JA (2007) Utilizing remote sensing and GIS to detect prairie dog colonies. Rangel Ecol Manag 60:45-53. https://doi.org/10.2111/05-114R2.1

Belgiu M, Drăgu L (2016) Random forest in remote sensing: A review of applications and future directions. ISPRS J Photogramm Remote Sens 114:24-31. https://doi.org/10.1016/j.isprsjprs.2016.01.011

Berhane TM, Lane CR, Wu Q, et al (2018a) Comparing pixel- and object-based approaches in effectively classifying wetland-dominated landscapes. Remote Sens 10:46. https://doi.org/10.3390/rs10010046

Berhane TM, Lane CR, Wu Q, et al (2018b) Comparing pixel- and object-based approaches in effectively classifying wetland-dominated landscapes. Remote Sens 10:46. https://doi.org/10.3390/rs10010046

Berhane TM, Lane CR, Wu Q, et al (2018c) Decision-Tree, Rule-Based, and Random Forest Classification of High-Resolution Multispectral Imagery for Wetland Mapping and Inventory. Remote Sens 2018, Vol 10, Page 580 10:580. https://doi.org/10.3390/RS10040580

Biggins DE, Miller BJ, Hanebury LR, et al (1993) A technique for evaluating black-footed ferret habitat. In: Management of prairie dog complexes for the reintroduction of the black-footed ferret. US Fish and Wildlife Service Biological Report. pp 73-88

Bivand R, Gebhardt A (2000) Implementing functions for spatial statistical analysis using the R language. J Geogr Syst 2:307-317. https://doi.org/10.1007/PL00011460

Boyaci D, Erdoğan M, Electrical FY-TJ of, 2017 U (2017) Pixel-versus object-based classification of forest and agricultural areas from multiresolution satellite images. Turkish J Electr Eng Comput Sci 25:365-375. https://doi.org/10.3906/elk-1504-261

Breiman L (2001) Random forests. Mach Learn 45:5-32. https://doi.org/10.1023/A:1010933404324

Breiman L, Friedman JH, Olshen RA, Stone CJ (2017) Classification and regression trees, 1st edn. Routledge, Boca Raton

Brevik EC, Slaughter L, Singh BR, et al (2020) Soil and Human Health: Current Status and Future Needs. Air, Soil Water Res 13:. https://doi.org/10.1177/1178622120934441

Butler DR (1995) Zoogeomorphology: animals as geomorphic agents. Zoogeomorphology Anim as geomorphic agents. https://doi.org/10.2307/3059700

Cepáková E, Hulová S (2002) Current distribution of the European souslik (Spermophilus 
Cohen J (1968) Weighted kappa: Nominal scale agreement provision for scaled disagreement or partial credit. Psychol Bull 70:213-220. https://doi.org/10.1037/h0026256

Congalton RG (2001) Accuracy assessment and validation of remotely sensed and other spatial information. Int J Wildl Fire 10:321-328. https://doi.org/10.1071/wf01031

500

501

502

503

504

505

506

507

508

509

510

511

512

513

514

515

516

517

518

519

520

521

522

523

524

525

526

527

528

529

530

531

532

533

534

535

536

Csorba G, Pecsenye K (1997) Nemzeti Biodiverzitás-monitorozó Rendszer X. Eml"osök és a genetikai sokféleség monitorozása. In: Magy. Természettudományi Múzeum, Budapest. https://scholar.google.com/scholar?hl=en\&as_sdt=0\%2C5\&q=A+Nemzeti+Biodiverzitás monitorozó + Rendszer + X. + Emlösök + és $+a+$ genetikai + sokféleség + monitorozása\&btnG $=$. Accessed 17 Jul 2021

Davidson AD, Lightfoot DC (2007) Interactive effects of keystone rodents on the structure of desert grassland arthropod communities. Ecography (Cop) 30:515-525. https://doi.org/10.1111/J.0906-7590.2007.05032.X

Delincé J (2017) Handbook on remote sensing for agricultural statistics. In: Delincé J (ed) Handbook on Remote Sensing for Agricultural StatisticsAgricultural Statistics. GSARS Handbook, Rome

Dormann CF, Elith J, Bacher S, et al (2013) Collinearity: A review of methods to deal with it and a simulation study evaluating their performance. Ecography (Cop) 36:27-46. https://doi.org/10.1111/j.1600-0587.2012.07348.x

Duro DC, Franklin SE, Dubé MG (2012) A comparison of pixel-based and object-based image analysis with selected machine learning algorithms for the classification of agricultural landscapes using SPOT-5 HRG imagery. Remote Sens Environ 118:259272. https://doi.org/10.1016/j.rse.2011.11.020

Erdos L, Tölgyesi C, Horzse M, et al (2014) Habitat complexity of the pannonian foreststeppe zone and its nature conservation implications. Ecol Complex 17:107-118. https://doi.org/10.1016/j.ecocom.2013.11.004

Ewacha MVA, Kaapehi C, Waterman JM, Roth JD (2016) Cape ground squirrels as ecosystem engineers: Modifying habitat for plants, small mammals and beetles in Namib Desert grasslands. Afr J Ecol 54:68-75. https://doi.org/10.1111/AJE.12266

Feldhamer G, Drickamer L, Vessey S, Merritt J (2007) Mammalogy: adaptation, diversity, ecology, 3rd edn. JHU Press, Baltimore

Gedeon CI, Boross G, Németh A, Altbäcker V (2012) Release site manipulation to favour European ground squirrel Spermophilus citellus translocations: Translocation and habitat manipulation. Wildlife Biol 18:97-104. https://doi.org/10.2981/10-124

Gedeon CI, Hoffmann IE, Váczi O, et al (2017) The role of landscape history in determining allelic richness of European ground squirrels (Spermophilus citellus) in Central Europe. Hystrix 28:240-246. https://doi.org/10.4404/hystrix-28.2-11823

Gomes Rodrigues H, Šumbera R, Hautier L (2016) Life in Burrows Channelled the Morphological Evolution of the Skull in Rodents: the Case of African Mole-Rats (Bathyergidae, Rodentia). J Mamm Evol 23:175-189. https://doi.org/10.1007/s10914015-9305-x 
Győri-Koósz B, Faragó S (2017) Az ürge (Spermophilus citellus) tápláléknövényei, mint potenciális elterjedési tényezők, ökológiai értékelésük alapján. Magy Apróvad Közlemények 13:161-175. https://doi.org/10.17243/mavk.2017.161

Hansell MH (1993) The Ecological Impact of Animal Nests and Burrows. Funct Ecol 7:5. https://doi.org/10.2307/2389861

Harper SJ, Batzli GO (1996) Effects of predators on structure of the burrows of voles. J Mammal 77:1114-1121. https://doi.org/10.2307/1382793

Hastie T, Tibshirani R, Friedman J (2017) The Elements of Statistical Learning, 2nd edn. Springer, New York

Haussmann NS (2017) Soil movement by burrowing mammals: A review comparing excavation size and rate to body mass of excavators. Prog Phys Geogr 41:29-45. https://doi.org/10.1177/0309133316662569

Hegyeli Z (2020) Spermophilus citellus. In: IUCN Red List Threat. Species 2020 e.T20472A91282380.

Hoogland J (2013) Conservation of the black-tailed prairie dog: saving North America's western grasslands. Island Press, Chicago

Hubbs AH, Karels T, Boonstra R (2000) Indices of Population Size for Burrowing Mammals. J Wildl Manage 64:296. https://doi.org/10.2307/3803002

Hut RA, Scharff A (1998) Endoscopie observations on tunnel blocking behaviour in the European ground squirrel (Spermophilus citellus). Zeitschrift fur Saugetierkd 63:377380

Janák M, Marhoul P, Mateju J (2013) Action Plan for the Conservation of the European Ground Squirrel Spermophilus citellus in the European Union List of contributors. European Commission

Jin S, Su Y, Gao S, et al (2018) The transferability of Random Forest in canopy height estimation from multi-source remote sensing data. Remote Sens 10:. https://doi.org/10.3390/rs10081183

Johnson DL (1990) Biomantle evolution and the redistribution of earth materials and artifacts. Soil Sci 149:84-102. https://doi.org/10.1097/00010694-199002000-00004

Johnson DL, Burnham JLH (2012) Introduction: Overview of concepts, definitions, and principles of soil mound studies. In: Special Paper of the Geological Society of America. pp 1-19

Katona K, Váczi O, Altbäcker V (2002) Topographic distribution and daily activity of the European ground squirrel population in Bugacpuszta, Hungary. Acta Theriol (Warsz) 47:45-54. https://doi.org/10.1007/BF03193565

Lillesand T, Kiefer WR, Chipman J (2015) Remote sensing and image interpretation., 7th edn. John Wiley \& Sons, Danvers

Lindtner P, Gömöryová E, Gömöry D, et al (2019) Development of physico-chemical and biological soil properties on the European ground squirrel mounds. Geoderma 339:8593. https://doi.org/10.1016/j.geoderma.2018.12.043

Mcdonald BLL, Stanley TR, Otis DL, et al (2011) Recommended Methods for Range-Wide 
Monitoring of Prairie Dogs in the United States. US Geol Surv Sci Investig Rep 2011506336

Meadows PS, Meadows A (1991) The environmental impact of burrowing animals and animal burrows : the proceedings of a symposium held at the Zoological Society of London on 3rd and 4th May 1990, 1st edn. Published for the Zoological Society of London by Clarendon Press, London

Pettorelli N, Laurance WF, O'Brien TG, et al (2014) Satellite remote sensing for applied ecologists: Opportunities and challenges. J Appl Ecol 51:839-848. https://doi.org/10.1111/1365-2664.12261

Plumptre AJ (2000) Monitoring mammal populations with line transect techniques in African forests. J Appl Ecol 37:356-368. https://doi.org/10.1046/j.1365-2664.2000.00499.x

QGIS Development T (2021) QGIS Geographic Information System: Open Source Geospatial Foundation Project

Qu L, Chen Z, Li M, et al (2021) Accuracy improvements to pixel-based and object-based LULC classification with auxiliary datasets from google earth engine. Remote Sens 13:453. https://doi.org/10.3390/rs13030453

R Core Team (2020) R: A language and environment for statistical computing. R Foundation for Statistical Computing, Vienna, Austria

Ramos-Lara N, Koprowski JL, Kryštufek B, Hoffmann IE (2014) Spermophilus citellus (Rodentia: Sciuridae). Mamm Species 913:71-87. https://doi.org/10.1644/913.1

Rokach L, Maimon O (2006) Ensemble Methods for Classifiers. In: Data Mining and Knowledge Discovery Handbook. Springer-Verlag, Boston, pp 957-980

Ruzic A (1978) Citellus citellus (Linaeus, 1766) - Der oder das Europäische Ziesel. In: Handbuch der Säugetiere Europas, Bd. 1, Nagetiere I. pp 123-144

Sandifer PA, Sutton-Grier AE, Ward BP (2015) Exploring connections among nature, biodiversity, ecosystem services, and human health and well-being: Opportunities to enhance health and biodiversity conservation. Ecosyst Serv 12:1-15. https://doi.org/10.1016/j.ecoser.2014.12.007

Šefferová S, Janák M, Vajda Z (2008) MANAGEMENT of Natura 2000 habitats: Pannonic sand steppes

Sequeira AMM, Bouchet PJ, Yates KL, et al (2018) Transferring biodiversity models for conservation: Opportunities and challenges. Methods Ecol Evol 9:1250-1264. https://doi.org/10.1111/2041-210X.12998

Sherman PW (1981) Kinship, demography, and belding's ground squirrel nepotism. Behav Ecol Sociobiol 8:251-259. https://doi.org/10.1007/BF00299523

Sibaruddin HI, Shafri HZM, Pradhan B, Haron NA (2018) Comparison of pixel-based and object-based image classification techniques in extracting information from UAV imagery data. IOP Conf Ser Earth Environ Sci 169:12098. https://doi.org/10.1088/1755$1315 / 169 / 1 / 012098$

Smalheiser NR (2017) Data literacy: How to make your experiments robust and reproducible, 1 st edn. Elsevier, Academic Press, London 
Stephenson PJ (2019) Integrating Remote Sensing into Wildlife Monitoring for Conservation. Environ Conserv 46:181-183. https://doi.org/10.1017/S0376892919000092

Stoeva E, Ivanov I, Stoev I, et al (2016) Successful reinforcement of the european souslik by Green Balkans NGO in "Sinite kamani”" Nature Park. In: Annuaire de l'Université de Sofia “St. Kliment Ohridski” Faculte de Biologie. University Press, Sofia, pp 153-165

Stokes E, Johnson A, Rao M (2010) Monitoring wildlife populations for management. In: Found. Success. https://www.researchgate.net/profile/ArlyneJohnson/publication/257363333_Module_7_Monitoring_Wildlife_Populations_for_Man agement_Background_Presentation_and_Exercises/links/00463525085e5ab4ca000000/ Module-7-Monitoring-Wildlife-Populations-for-Management-. Accessed 17 Jun 2021

Šumbera R, Mazoch V, Patzenhauerová H, et al (2012) Burrow architecture, family composition and habitat characteristics of the largest social African mole-rat: The giant mole-rat constructs really giant burrow systems. Acta Theriol (Warsz) 57:121-130. https://doi.org/10.1007/S13364-011-0059-4

Swaisgood RR, Montagne JP, Lenihan CM, et al (2019) Capturing pests and releasing ecosystem engineers: translocation of common but diminished species to re-establish ecological roles. Anim Conserv 22:600-610. https://doi.org/10.1111/acv.12509

Swinbourne MJ, Taggart DA, Swinbourne AM, et al (2018) Using satellite imagery to assess the distribution and abundance of southern hairy-nosed wombats (Lasiorhinus latifrons). Remote Sens Environ 211:196-203. https://doi.org/10.1016/j.rse.2018.04.017

TIBCO Software Inc. (2018) Statistica (data analysis software system), version 13.

Váczi O, Varga I, Bakó B (2019) A Nemzeti Biodiverzitás-monitorozó Rendszer eredményei II. - Gerinces állatok. Körös-Maros Nemzeti Park Igazgatóság, Szarvas

Velasco M (2009) A Quickbird's eye view on marmots. International Institute for Geoinformation science and Earth Observation

Vlachopoulos O, Leblon B, Wang J, et al (2020a) Delineation of crop field areas and boundaries from UAS imagery using PBIA and GEOBIA with random forest classification. Remote Sens 12:1-24. https://doi.org/10.3390/RS12162640

Vlachopoulos O, Leblon B, Wang J, et al (2020b) Delineation of Bare Soil Field Areas from Unmanned Aircraft System Imagery with the Mean Shift Unsupervised Clustering and the Random Forest Supervised Classification. Can J Remote Sens 46:489-500. https://doi.org/10.1080/07038992.2020.1763789

Wang X, Zhang F, Kung H te, Johnson VC (2018) New methods for improving the remote sensing estimation of soil organic matter content (SOMC) in the Ebinur Lake Wetland National Nature Reserve (ELWNNR) in northwest China. Remote Sens Environ 218:104-118. https://doi.org/10.1016/j.rse.2018.09.020

Weddell BJ (1989) Dispersion of Columbian Ground Squirrels (Spermophilus columbianus) in Meadow Steppe and Coniferous Forest. J Mammal 70:842-845. https://doi.org/10.2307/1381725

Wenger SJ, Olden JD (2012) Assessing transferability of ecological models: An underappreciated aspect of statistical validation. Methods Ecol Evol 3:260-267. https://doi.org/10.1111/j.2041-210X.2011.00170.x 
Whitford WG, Kay FR (1999) Biopedturbation by mammals in deserts: A review. J Arid Environ 41:203-230. https://doi.org/10.1006/jare.1998.0482

Willcox D, Nash HC, Trageser S, et al (2019) Evaluating methods for detecting and monitoring pangolin (Pholidata: Manidae) populations. Glob Ecol Conserv 17:1-25. https://doi.org/10.1016/j.gecco.2019.e00539

Wilschut LI, Addink EA, Heesterbeek JAP, et al (2013) Mapping the distribution of the main host for plague in a complex landscape in kazakhstan: An object-based approach using SPOT-5 XS, landsat 7 ETM+, SRTM and multiple random forests. Int J Appl Earth Obs Geoinf 23:81-94. https://doi.org/10.1016/j.jag.2012.11.007

Wilschut LI, Heesterbeek JAP, Begon M, et al (2018) Detecting plague-host abundance from space: Using a spectral vegetation index to identify occupancy of great gerbil burrows. Int J Appl Earth Obs Geoinf 64:249-255. https://doi.org/10.1016/j.jag.2017.09.013

$\mathrm{Xu}$ Y, Goodacre R (2018) On Splitting Training and Validation Set: A Comparative Study of Cross-Validation, Bootstrap and Systematic Sampling for Estimating the Generalization Performance of Supervised Learning. J Anal Test 2:249-262. https://doi.org/10.1007/s41664-018-0068-2

Zolyomi B, Fekete G (1994) The Pannonian loess steppe: differentiation in space and time. Abstr Bot 18:29-41

\section{List of figure captions}

Figure 1. Location of studied souslik colonies in Hungary, and area and spatial position of images used for image processing.

Supplementary Figure S1. Point pattern analysis for the four sites. $G_{o b s}(r)$ (with black solid line) is the observed distribution of the nearest neighbour distribution function; $G_{t h e o}(r)$ (with dashed red line) is the theoretical distribution of complete spatial randomness; $F_{o b s}(r)$ is the observed distribution of empty space function; $F_{\text {theo }}(r)$ is the theoretical distribution of empty space function; G or $F_{\text {hi OR lo }}(r)$ (with grey shaded area) are the upper (hi) and lower (lo) envelope of the theoretical distribution of complete spatial randomness or empty space function; $\mathrm{r}$ is distance in metres. 
690 Supplementary Figure S2. How different tasks are connected during the process of 691 identification of souslik burrows from UAV imagery through Spectral Normalization to RF 692 classification and test of model stability. Symbols (shapes) represent the following meanings: 693 Ellipses are for start or end points in the process; rectangles are for steps in the process; 694 parallelograms and rhombuses are for inputs or outputs in the process.

695

\section{Table legends}

697 Table 1. List and description of input variables (predictors) for the four RF models (M1.1, 1.2,

698 $2.1,2.2)$.

699 Table 2. Overall accuracies and kappa statistics, per-class BURROW kappa for S (K KURROW and $\mathrm{P}\left(K_{B U R R O W}^{P}\right)$, and their parameter estimates for each RF model. Coefficient of variation

701 (CV\%), confidence intervals (CI).

Table 3. How per-class (BURROW) Cohen's kappa, Standard Deviation (SD), and Coefficient of variation (CV\%) for Precision and Sensitivity change during the 10-time iteration. For each iteration different training (63\%) and test (37\%) subsets were selected randomly from the complete dataset.

707 Figures (including supplementary figures): In separate files. 
Figures
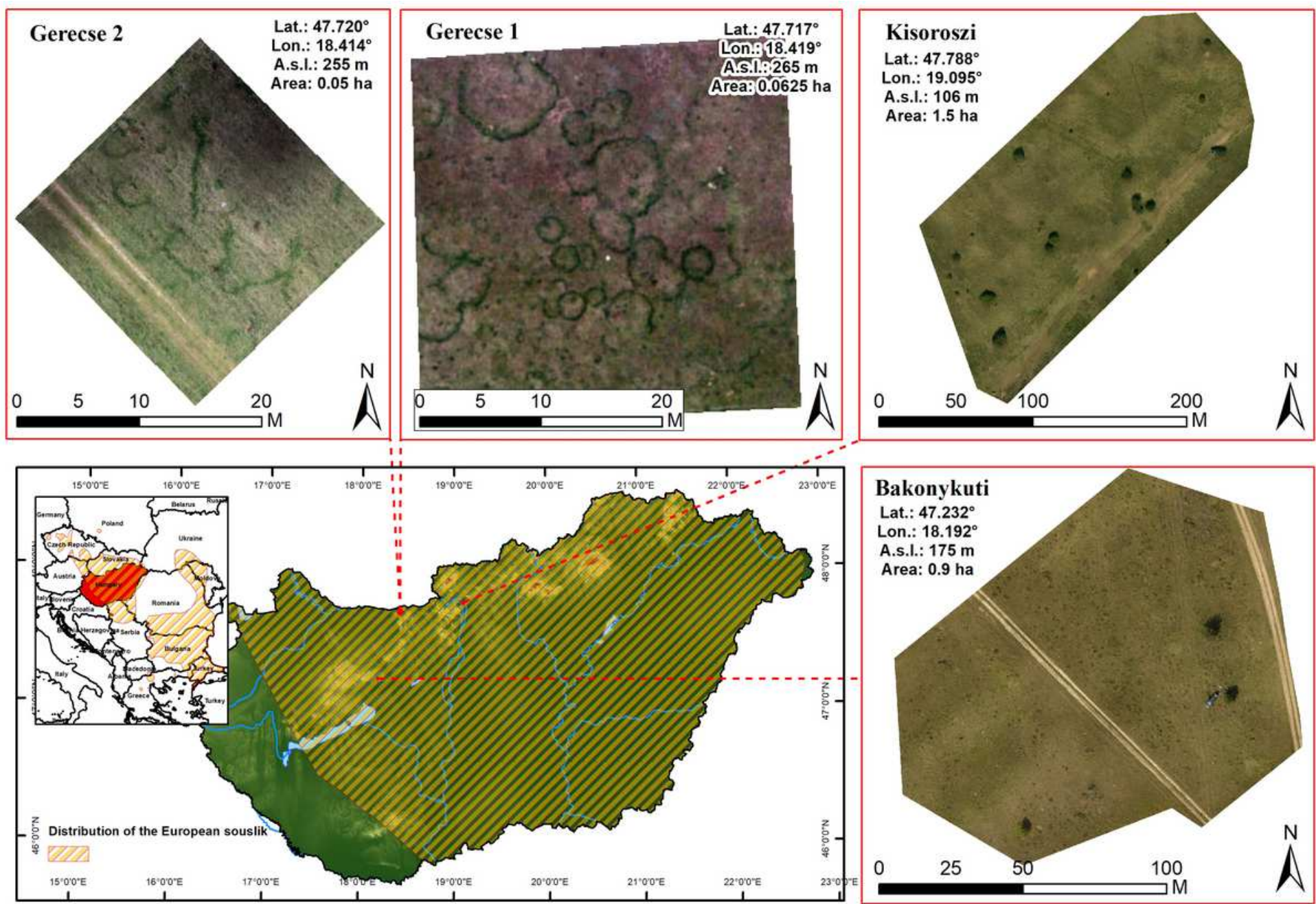

\section{Figure 1}

Location of studied souslik colonies in Hungary, and area and spatial position of images used for image processing.

\section{Supplementary Files}

This is a list of supplementary files associated with this preprint. Click to download.

- SupplemementaryFigureS1.pdf

- SupplementaryFigureS2.pdf 